\section{Lélia Gonzalez: \\ Da Importância \\ de Reconhecermos \\ as Desigualdades \\ Raciais, Sociais e \\ de Gênero no Brasil}

\section{Resumo}

Lélia Gonzalez é importante ícone da militância negra contemporânea, por sua atuação e por sua influência na formação de novas lideranças. Do fato, desdobra-se o interesse em conhecer e difundir as ideias da intelectual, assim, o objetivo do presente artigo é abordar elementos chaves do pensamento da intelectual militante Lélia Gonzalez, contudo, diante do cenário que estamos vivendo (2020), objetivou-se, ainda, finalizar com reflexões sobre a Necropolítica, conceito criado e difundido por Achile Mbembe (2018), e os impactos da Covid-19 na população afrodescendente no país. As fontes são a biografia de Alex Ratts e Flávia Rios (2010) e pronunciamento da ativista da ocasião da discussão da Constituição Federal, em comissão específica. De forma geral, foi possível identificar entre as pautas da intelectual a construção e manutenção histórica da situação de vulnerabilidade da população negra brasileira, evidenciado ainda mais em tempos de pandemia e de omissão política do Estado.

Palavras-chave: Lélia Gonzalez, Desigualdades, Políticas Públicas, Covid-19.

\section{Abstract}

Lélia Gonzalez is an important icon of contemporary afro-brazilian activism, for her performance and her influence in the formation of new leaders. In fact, the interest in knowing and spreading the intellectual's ideas unfolds, thus, the objective of this article is to address key elements of the thinking of the militant intellectual Lélia Gonzalez, however, in view of the scenario we are living in (2020), we also aimed ends with reflections on Necropolitics, a concept created and disseminated by Achile Mbembe (2018), and the impacts of Covid-19 on the Afro-descendant population in the country. The sources are the biography of Alex Ratts and Flávia Rios (2010) and the activist's
Prof. ${ }^{a}$ Dr. ${ }^{a}$ Mírian Cristina de Moura Garrido

Pós-doutoranda da Universidade Federal de São Paulo em História, Doutora e Mestra pela Universidade Estadual Paulista, campus de Assis. A autora atua nos temas: livros didáticos; pós- abolição; biografias; movimento negro; e Moçambique. 
statement on the occasion of the discussion of the Federal Constitution, in a specific commission. In general, it was possible to identify among the guidelines of the intellectual the construction and historical maintenance of the vulnerability of the afro-brazilian population, further evidenced in times of pandemic and political omission of the State.

Key-works: Lélia Gonzalez, Inequality, Public Politics, Covid-19.

\section{Introdução}

Quando pela primeira vez discutiu-se minha participação neste dossiê e os temas a serem abordados, a escolha recaiu sobre a trajetória da militante Lélia Gonzalez. Personagem importante dentro da militância brasileira, cujo trabalho e reflexões sobre eles vem sendo abordados por mim em outras oportunidades.

$\mathrm{Na}$ época, no que parece o longínquo mês de fevereiro, ouvíamos falar do Covid-19 como uma doença distante, que acometia a China e começava a fazer vítimas na Europa. No final da primeira quinzena do mês seguinte o que era uma "gripezinha" segundo autoridades, foi reconhecida como pandemia e modificou nossa forma de viver.

Neste contexto, falar de Lélia Gonzalez não perde completamente o sentido. Mas os caminhos para que possa esse esforço ter um maior significado, este sim, foi alterado. Assim, o objetivo do presente artigo é abordar elementos chaves do pensamento da intelectual militante Lélia Gonzalez, e finalizar com reflexões sobre a Necropolítica, conceito criado e difundido por Achile Mbembe (2018), e os impactos da Covid-19 na população afrodescendente no país. Reconheço, porém, que as discussões se dão ainda quando pouco conhecemos sobre os números reais dos infectados e falecidos no país - se é que um dia saberemos -, o que não diminui a potencialidade de reflexões por parte dos intelectuais das ciências humanas.

\section{Trajetória de Lélia Gonzalez}

A compreensão da trajetória de Lélia Gonzalez é fundamental para entendimento do espaço ocupado pela experiência na formação da intelectual e, por conseguinte, das pautas e discussões por ela definidas e elaboradas.' As considerações aqui apresentadas tomam como fonte a biografia produzida sobre a militante de Alex Ratts e Flavia Rios (2010) e informações obtidas em textos e discursos produzidos pela própria personagem.

Lélia nasceu em fevereiro de 1935, em uma família grande de dezoito filhos, sendo ela a penúltima. Sua mãe era indígena, ocupando a função de doméstica, e seu pai negro, trabalhava como ferroviário. Lélia Gonzalez narra uma vida de muito trabalho entre seus irmãos, tendo sido beneficiada com um estudo de maior longevidade e de qualidade por questões excepcionais, tais como o fato de ser a mais nova, pela intervenção de uma família para qual a mãe prestou serviços de ama de leite, e pelo fato do irmão ter obtido êxito no futebol carioca (RIOS; RATTS, 2010, p.24-31). A formação privilegiada, se comparada a realidade da maioria dos negros brasileiros, que the possibilitou formação universitária e domínio de línguas estrangeiras, legou a Lélia não apenas conhecimento formal, mas uma rejeição do pertencimento racial:

\footnotetext{
Fiz escola primária e passei por aquele processo que eu chamo de lavagem cerebral dado o discurso pedagógico brasileiro, porque, na medida em que eu aprofundava meus conhecimentos, eu rejeitava cada vez mais minha condição de negra. E, claro, passei pelo ginásio, científico, esses baratos todos. (GONZALEZ, 1979 Apud RIOS; RATTS, 2010, p. 31)
}

Graduada em História, Geografia e Filosofia pela Universidade Estadual do Rio de Janeiro (1958 e 1962, na época, Universidade Estadual da Guanabara), Lélia Gonzalez foi professora, inicialmente em colégios de nível médio e, poste-

1 Esforço semelhante já foi por mim realizado e pode ser acessado pelo leitor, caso deseje uma discussão mais aprofundada. Cf:: GARRIDO, M. C. de M. Atuação militante de Lélia Gonzalez na discussão da Constituição Federal de 1988. TEMPO E ARGUMENTO, v. 10, p. 435-463, 2018. 
riormente, universitário. Fotos do acervo pessoal de Ana Felippe (disponibilizados aos biógrafos) mostram uma Lélia Gonzalez, professora, posando na formatura com vestido recatado e tradicional de época, peruca lisa e penteada. A adoção de padrões de beleza e comportamento são narrados pela militante como forma de se fazer pertencer aos espaços notadamente não-negros, tal como a universidade.

Outro elemento de rejeição étnico-racial, segundo a própria Lélia, teria sido a escolha do marido, um colega de faculdade branco espanhol. Mas é, exatamente, o matrimônio que redefine o pertencimento da futura militante. Recusada como esposa legítima pela família do marido e questionada por ele sobre sua falta de pertencimento, a trajetória de Lélia Gonzalez toma novos rumos.

A relação conturbada com a família do marido (Luiz Carlos Gonzalez) e o falecimento trágico deste (não há referência de data do casamento ou falecimento) e de sua mãe (1967), parecem ter se tornado estopins para o envolvimento de Lélia em discussões políticas e uma (re)apreensão de sua trajetória. Surgiria dali a militante das causas negras e feministas. Nesse tempo, Lélia ainda casaria com outro homem, "[Vicente Marota] um mulato que procurava fugir de si próprio" (p. 59), o que resultaria na busca de ajuda na psicanálise.

Tive que parar num analista, fazer análise etc. e tal, e a análise neste sentido me ajudou muito. A partir daí fui transar meu povo mesmo, ou seja, fui transar candomblé, macumba, essas coisas que eu chamava de primitivas. Manifestações culturais que eu, afinal de contas, com uma formação em filosofia, transando uma forma cultural ocidental tão sofisticada, claro que não podia olhar como coisas importantes. Mas enfim, voltei às origens, busquei minhas raízes. (PEREIRA; HOLLANDA, 1979 Apud RIOS; RATTS, p. 60-61)

A partir daí, Lélia passa a reinterpretar a experiência diaspórica africana na América. Dentre elas, a questão religiosa, aproximando-se do candomblé, que "se tornou uma refe- rência poética e imagética para Lélia Gonzalez, presente aqui e acolá nos seus textos, inclusive nos ensaios de caráter mais político" (RIOS; RATTS, p. 64).

Sua nova postura acompanhava uma mudança estética (cabelos "black power" e roupas de cores vivas, identificados com a cultura negra estadunidense e africana), como também uma ação de intervenção. Nesse sentido, articula cursos sobre cultura afro-brasileira, produz academicamente sobre os temas que agora the ocupavam a atenção, e participa de entidades negras de cunho político e cultural (tais como o Grêmio Recreativo de Arte Negra Escola de Samba Quilombo e o Movimento Unificado Contra a Discriminação Racial).

Característico desse movimento negro dos anos 1970 e 1980, Lélia como liderança se torna, também, indivíduo de referência dentro e fora do movimento, tendo suas ideias expostas em jornais negros e em periódicos de grande circulação. Esses elementos não passam despercebido da vigilância imposta pela Ditadura Militar (BARRETO, 2007), ao mesmo tempo, são característicos do movimento de formação da militância negra no Brasil na década de 1970, que passa a se estender por todo território nacional (ALBERTI; PEREIRA, 2007).

Grupos estes que se unem em prol de uma pauta, cujo destaque vai para: denúncia do mito da democracia racial; busca por uma atuacão política e apresentação de demandas aos poderes públicos; a exortação de uma cultura afro-brasileira forjada na experiência escravista e pós-escravista; denúncia da discriminação racial, inclusive institucional; a importância da educação e valorização de organização de eventos, congressos e centros de estudos; a estratégia de aglutinar os mestiços nos assuntos de interesses raciais; e a educação do negro (PEREIRA, 2013; GARRIDO, 2017).

Ademais, mesmo que reticente com o comprometimento de partidos às questões raciais, na profusão do que foi o processo de redemocratização, Lélia Gonzalez filia-se ao Partido dos Trabalhadores (PT), recém-criado e originário da classe trabalhadora de São Paulo 
que ganhou destaque nacional pelas greves realizadas no ABC no final da década de 1978. Entrevistas dadas no período de sua filiação e na campanha para deputada federal, em 1982, indicam a crença da ativista no caráter diferenciado do PT - uma vez que o partido seria oriundo das classes mais baixas e trabalhadoras -, não havendo "no partido um senhor" (Apud RIOS; RATTS, p. 116). Embora não obtenha sucesso no pleito, torna-se assessora de Benedita Silva que foi eleita vereadora em 1983 pelo PT-RJ. Em 1986, agora filiada ao PDT, cuja articulação de Leonel Brizola, Darcy Ribeiro e Abdias do Nascimento pesaram na escolha partidária, Lélia Gonzalez busca, mais uma vez, aprovação eleitoral para deputada estadual, novamente não é eleita, encerrando aqui as tentativas de obter cargo político eletivo.

\section{Lélia Gonzalez: pelo o que luta a mulher negra militante?}

O trabalho com intelectuais do movimento negro tem ocupado meus esforços desde 2013 , quando iniciei o doutoramento com o objetivo de compreender a formação desse grupo, suas visões de mundo e suas demandas. Ao longo do percurso de pesquisa ficou evidente a dificuldade de encontrar fontes e acervos organizados sobre entidades ou agentes pertencentes a elas. Não integrando os grupos hegemônicos seja intelectual, seja econômico -, as memórias dessas pessoas ficam restritas aos núcleos mais próximos (militantes ou parentes), quando muito nas entidades que formaram.

Neste cenário pouco promissor, contudo, algumas brechas foram encontradas. Primeiro, o esforço hercúleo dos pesquisadores Amílcar Pereira e Verena Alberti (2007), que entrevistaram militantes de diferentes partes do país e a sistematizaram em formato livro (em projeto em parceria com CPDOC-FGV). Segundo, o surgimento de obras direcionadas a publicizar e visibilizar uma memória afro-brasileira, caso da editora Selo Negro e sua coleção Retratos do Brasil Negro, que tem lançado biografias de militantes e entidades negras contempo- râneas. Por último, o acesso à textos, discursos, entrevistas concedidos e produzidos pelos próprios militantes que foi possível encontrar via internet.

Esse foi o corpo documental para compreender as visões de mundo e as estratégias de atuação dos militantes brasileiros contemporâneos. Foi por essa via que acessei Lélia Gonzalez e apresento alguns pontos do pensamento da intelectual a seguir. Estes pontos, talvez tenham sido sumarizados quando da participação de Lélia Gonzalez na discussão do texto para a Constituição Federal de 1988, onde palestrou no dia 28 de abril de 1987, na $7^{\circ}$ Reunião da Subcomissão dos Negros, Populações Indígenas, Pessoas deficientes e Minorias.

Na ocasião, seu discurso enfatizou a negação da importância do negro na construção da sociedade; a prioridade histórica dada aos brancos na imigração como forma de embranquecimento da população brasileira; uma conduta política e cultural das instituições e da sociedade baseada na teoria positivista e darwinista social; a existência de uma sociedade hierárquica que atinge o negro, mas em especial, a mulher negra e a hierarquização dos valores que tende a tratar a cultura negra e indígena como folclore; uma cultura que domina a história europeia, e que pouco conhece dos povos pré-colombianos e africanos; a política como instrumento de manutenção do negro como trabalhador não-qualificado; e a consequente marginalização do negro no que concerne ao trabalho, acesso à terra, sistema carcerário, prostituição, dentro desse processo de preterimento.

Em seu discurso, a militante e intelectual reforça, portanto, a construção histórica da marginalização da população negra brasileira. Como pode ser observado no trecho a seguir quando indica que os mecanismos republicanos não foram capazes - porque assim não o foi desejado - de reverter o cenário estabelecido desde de 1888:

Então é que vamos perceber que nesse período que vem de 1888 para cá as grandes promessas da campanha abolicionis- 
ta não se realizaram; aquelas promessas de que o negro pode ser doutor, que pode ser isto e aquilo, que pode pretender a uma ascensão social, nada disso aconteceu. Porque, efetivamente, vamos verificar que os mecanismos jurídicos criados pela República positivista brasileira, no sentido de manutenção do negro na condição de trabalhador não-qualificado e alijado do centro da produção econômica. Não é por acaso que essa população acabou por ser atirada na periferia do sistema de produção que se instalou no País, um modo de produção capitalista e a população negra, o conjunto dos trabalhadores negros vão constituir uma espécie de exército de reserva ou até mesmo a população marginal crescente, que só tem acesso em termos de trabalho a periferia do sistema, ou seja; aos setores satelitizados da economia brasileira. (DIÁRIO DA ASSEMBLÉIA NACIONAL CONSTITUINTE - SUPLEMENTO AO N.62, 1987, p. 121 - grifos meus)

Para reforcar seus argumentos a militante usa como recurso considerações sobre o censo de 1980, quando então, o estado retomava por pressão do movimento negro, inclusive - o critério cor entre os dados recolhidos:

O censo de 1980 está aí demonstrando que na nossa sociedade a hierarquia permanece. No que diz respeito ao acesso aos melhores salários nas diferentes profissões, vamos encontrar a relação hierárquica ao acesso aos melhores salários nas diferentes profissões, vamos encontrar a relação hierárquica e no primeiro plano está o homem branco, abaixo a mulher branca, em seguida o homem negro e, finalmente a mulher negra. É importante ressaltar que o racismo que existe na nossa sociedade tem que ser encarado olho no olho. Chega de ficarmos disfarçando que somos democratas raciais, que batemos no ombro do pretinho, mas não admitimos que case com nossas filhas, porque é demais! Chega desta postura paternalista que marca todas as relações da sociedade brasileira, as relações dos donos do poder com relação aos explorados, oprimidos e aos dominados; relações de compadrio, relações pessoais. (DIÁRIO DA ASSEMBLÉIA NACIONAL CONSTITUINTE - SUPLEMENTO AO N.62, 1987, p. 121)

No encerramento de sua palestra, Lélia Gonzalez deixa claro que o que estava em jogo era a concretização efetiva da isonomia social. Isonomia ali significava equidade, justiça, igualdade. Juridicamente, tratava-se de compreender que todos são iguais perante a lei, mas que situações desiguais devem ser compreendidas em suas especificidades, uma vez que não deve haver distinção de classe, grau ou poder econômico entre os homens e mulheres. Lélia recorre ao pedido de isonomia para a efetivação real de uma nação que considera a existência das desigualdades e se organiza pensando em superá-las.

O apresentado em frente aos deputados e senadores constituintes já estava presente em outros textos de Gonzalez (1980;1982), bem como, tem sido destacado por autores que analisam a obra da personagem (BARRETO, 2005; VIANA 2006; BAIRROS, 2006; CARDOSO, 2014). Em resumo, não é possível pensar em discutir políticas públicas sem levar em consideração o mito da democracia racial; o processo histórico que produziu e mantêm (ainda hoje) a desigualdade racial; e classe, raça e gênero como categorias importantes para pensar desigualdade.

E, por mais triste que seja, quando recorremos aos índices atuais constatamos a manutenção deste cenário. Assim, as mulheres negras são as que tem menor acesso à exames clínicos voltados para a saúde da mulher; necessitam de maior amparo de políticas assistências, tais como o Bolsa Família; as que possuem maior taxa de desemprego de todas as categorias analisadas (homens, mulheres, brancos, negros); são as que possuem menor renda média, em 2009 somavam 544,00 reais mensais, contra 833,50 dos homens negros, 975,00 das mulheres brancas e 1491,00 reais dos homens brancos (PNAD, 2019 Apud IPEA, 2011). Em suma, quando cruzadas as informações de classe, raça e gênero, as mulheres negras brasileiras estão na pior situação de vulnerabilidade do país. 


\section{Lélia Gonzalez, Necropolítica e Covid-19: à guisa de reflexões sobre políticas públicas}

Aliado as informações até aqui postas, para que possamos avançar nas reflexões, é possível pensar ainda o conceito de Necropolítica. Dialogando com teóricos contemporâneos, em especial com Michel de Foucault, o camaronês Achile Mbembe (2018) afirma que essa "morte como forma de fazer política" (ou seja, a Necropolítica) é a habilidade do poder político em determinar que a soberania é exercer o controle sobre a mortalidade, definir quem deve viver e quem não deve viver, nas palavras do autor, a soberania permite definir quem é descartável e quem não é.

Segundo Mbembe, o Estado, em especial ao longo do século XX e XXI, tem criado dispositivos de controle e de guerra que extrapolam experiências anteriores, que dotam mecanismos de imposição sobre o inimigo, incluindo a morte, a partir de uma racionalidade própria. Em outros termos, uma racionalidade que define quem pode ser sacrificado em nome de determinada causa, nos termos da atual autoridade máxima do Estado brasileiro: "Vão morrer alguns do vírus? Sim, vão... Eu acho que ela nos deixa. Agora não podemos criar esse clima todo que está aí. Prejudica a economia!" (Apud AZEVEDO, 2020).

De acordo com a Associação Brasileira de Saúde Coletiva, em seu site, as doenças não são entidades democráticas, portanto, no cenário da pandemia do Covid-19 determinados segmentos sociais estão mais expostos. É o caso da população negra brasileira, que a além das comorbidades existentes em todos os grupos, luta ainda contra o racismo estrutural. Em reportagem realizada com diferentes pesquisadores ligados à temática racial, a ABRASCO aponta questões da precariedade na habitação, do subemprego, do limite de acesso à saúde, e a manutenção da atividade profissional em tempos de quarentena, como elementos que penalizam de forma mais aguda o grupo (ABRASCO, 2020). Para enfatizar o pensamento, cito a seguir a fala de Edna Araújo, professora da Universidade Estadual de Feira de Santana, epidemiologista e uma das coordenadoras do GT Racismo e Saúde da Abrasco:

No Brasil, o enfrentamento à pandemia da Covid-19 tem desvelado não somente a insuficiência do nosso sistema de saúde, aliás condição comum a muitos sistemas de saúde do mundo frente a uma pandemia, mas também a desigualdade social oriunda da alta concentração de renda e do racismo nas suas mais variadas formas, que fazem com que o nascer, viver, adoecer e morrer da população negra sejam mediados por condições de miserabilidade, de privação de direitos, de moradia e de emprego formal. (Apud ABRASCO, 2020)

Considerações semelhantes estão sendo apontadas em outros países, e reforçam argumentos para nosso contexto. Thiago Amparo (2020), em texto para a Folha de S.Paulo, postada online também pelo Geledés, apresenta alguns destes dados para os Estados Unidos e para o Brasil. Afirma o autor:

Nos ombros de mulheres negras recai desproporcionalmente os cuidados de sua família e serviços precarizados. Doenças respiratórias são agravadas por condições socioeconômicas afetando desproporcionalmente negros. Isso sem citar a extensa literatura que mostra como médicos gastam menos tempo e recursos com pacientes negros do que brancos.

Mede-se racismo por quão descartável é o corpo negro. Se a Covid-19 desnuda as feridas do racismo que estrutura nossa desigualdade, curar esta pandemia pressupõe, antes de tudo, expô-las. (AMPARO, 2020)

E é nestes termos que proponho o reencontro com Lélia Gonzalez. Que a população negra, mulheres e homens, tenham do Estado aquilo que era solicitado na reunião do 28 de abril de 1987, a isonomia, ou seja, equidade, justiça, igualdade; uma forma de fazer política que compreenda as características específicas de cada grupo, e planeje meios de superarmos o impacto da pandemia de acordo com o grau de vulnerabilidade de cada grupo. 


\section{Referências}

ABRASCO - Associação Brasileira de Saúde Coletiva. População negra e Covid-19: desigualdades sociais e raciais ainda mais expostas. Disponível em: <https://www.abrasco.org.br/site/ outras-noticias/sistemas-de-saude/populacao-negra-e-covid-19-desigualdades-sociais-e-raciais-ainda-mais-expostas/46338/>. Acesso em: 27/04/2020.

ALBERTI, V;: PEREIRA, A. A. Histórias do movimento negro no Brasil: depoimentos ao CPDOC. Rio de Janeiro: Pallas; CPDOC-FGV, 2007.

AMPARO, T. Por que a Covid-19 é tão letal entre os negros? Disponível em: <https://www.geledes. org.br/por-que-a-covid-19-e-tao-letal-entre-os-negros/>. Acesso em: 20/04/2020.

BAIRROS, L. Lembrando Lélia Gonzalez. In:WERNECK, J.; MENDONCCA, M.; WHITE, E. (Org.). O livro da saúde das mulheres negras: nossos passos vêm de longe. Rio de Janeiro: Pallas; Criola; Global Exchange, 2006, p. 42-61.

BARRETO, R. de A. Aquela "negrinha" atrevida: Lélia Gonzalez e o movimento negro brasileiro. In: FERREIRA, J.; REIS, D. A. (org) Revolução e democracia (1964...). Rio de Janeiro: Civilização Brasileira, 2007.

BARRETO, R. de A. Enegrecendo o feminismo ou feminizando a raça: narrativas de libertação em Angela Davis e Lélia Gonzáles. Dissertação (Mestrado em História Social da Cultura) - Centro de Ciências Sociais, Pontifícia Universidade Católica do Rio de Janeiro, Rio de Janeiro, 2005.

CARDOSO, C. P. Amefricanizando o feminismo: o pensamento de Lélia Gonzalez. Revista Estudos Feministas, Florianópolis, v. 22, n. 3, p.965-986, set. 2014.

Diário da Assembléia Nacional Constituinte - Suplemento ao n.62. [ $7^{\circ}$ Reunião da Subcomissão dos Negros, Populações Indígenas, Pessoas deficientes e Minorias] Disponível em <http://imagem.camara.gov.br/Imagem/d/pdf/ sup62anc20mai1987.pdf\#page $=1201987>$. Publicado em 20/05/1987.
GARRIDO, M. C. M. Nas constituições dos discursos sobre afro-brasileiros: uma análise histórica da ação de militantes negros e dos documentos oficiais voltados à promoção do negro brasileiro (1978 a 2010). Tese de Doutorado em História, Universidade Estadual Paulista "Julio de Mesquita Filho", Assis, 2017

Atuação militante de Lélia Gonzalez na discussão da Constituição Federal de 1988. TEMPO E ARGUMENTO, v. 10, p. 435-463, 2018

GONZALEZ, L. Racismo e sexismo na sociedade brasileira. Apresentado na Reunião do Grupo de Trabalho "Temas e Problemas da População Negra no Brasil", IV Encontro Anual da Associação Brasileira de Pós-graduação e Pesquisa nas Ciências Sociais, Rio de Janeiro, v. 31, 1980.

GONZALÉZ, L.; HASENBALG, C. Lugar de Negro. Rio de Janeiro: Marco Zero, 1982.

INSTITUTO DE PESQUISA ECONÔMICA E APLICADA. IPEA. Retratos das Desigualdades de Gênero e Raça. 4.ed. Brasília: Ipea, 2011.

MBEMBE, A. Necropolítica: biopoder, soberania, estado de exceção, política de morte. São Paulo: $\mathrm{N}-1$ edições, 2018.

PEREIRA, A. A. O mundo negro: relações raciais e a constituição do movimento negro contemporâneo no Brasil. Rio de Janeiro: Pallas, Faperj, 2013.

RATTS, A.; RIOS, F. Lélia Gonzalez. São Paulo: Selo Negro, 2010.

VIANA, E. do E. S. Relações raciais, gênero e movimentos sociais: o pensamento de Lélia Gonzalez (1970-1990). Dissertação (Mestrado em História Comparada) - Instituto de Filosofia e Ciências Sociais, Universidade Federal do Rio de Janeiro, Rio de Janeiro, 2006.

AZEVEDO, R. Bolsonaro Sugere que ajudou a imunizar o país ao agir como irresponsável! Disponivel em: https://noticias.uol.com.br/colunas/ reinaldo-azevedo/2020/03/22/bolsonaro-sugere-que-ajudou-a-imunizar-o-pais-ao-agir-como-irresponsavel.htm. Acesso em: 29/04/2020. 
